\title{
A LEI ANTI-GAY RUSSA: DEMARCACOÕES E GOVERNO DOS CORPOS NO MUNDIAL DE ATLETISMO 2013
}

\author{
Fabio Zoboli \\ Universidade Federal de Sergipe, Aracaju, Sergipe, Brasil \\ Elder Silva Correia \\ Universidade Federal de Sergipe, Aracaju, Sergipe, Brasil \\ Renato Izidoro da Silva \\ Universidade Federal de Sergipe, Aracaju, Sergipe, Brasil \\ Tammy Rocha Costa \\ Universidade Federal de Sergipe, Aracaju, Sergipe, Brasil
}

\begin{abstract}
Resumo
Artigo que objetiva investigar as demarcações e governo dos corpos no que tange as questões de gênero ocorridas no Mundial de Atletismo de Moscou no ano de 2013 frente as polêmicas causadas pela lei anti-gay russa. Tratou-se de um estudo de abordagem qualitativa feita a partir de uma pesquisa descritivo-exploratória. Os dados empíricos utilizados para conjecturar os objetivos do texto foram retirados das publicações feitas no portal de internet "globo.com". Nossa análise se ateve a 12 reportagens e foi feita por meio de dois temas: "manifestações/protestos" e "polêmica Isinbayeva". Como resultado, observamos que as manifestações de atletas foram no sentido de clamar contra seu apagamento singular frente a uma política que exige um sujeito "universal".
\end{abstract}

Palavras-chave: Mundial atletismo Rússia 2014. Lei anti-gay. Desporto. Homossexualidade.

\section{Introdução}

O campeonato Mundial de Atletismo de 2013 ocorrido na cidade de Moscou entre os dias 10 e 18 de agosto foi marcado principalmente por repressões e proibições no que tange às questões ligadas a relações sexuais heteronormativas. Isso aconteceu pois 2 meses antes do evento foi declarada, pelo presidente Vladmir Putin, a lei anti-gay na Rússia, aprovada pela câmera baixa do Parlamento russo por votação unânime de 436 votos a 0 .

A lei proíbe divulgações sobre a homossexualidade para menores de 18 anos de idade. De acordo com o Artigo 6.21 do Código de Violações Legais Administrativas da Federação Russa, é permitido ao governo multar pessoas acusadas de divulgar "propaganda de relações sexuais não tradicionais entre menores", sendo cabível multa ou detenção. Essa lei traz um "ar" de intolerância, preconceito e até mesmo de crime. Em contraponto, a Rússia, em sua constituição, discursa em defesa da igualdade e pela livre expressão. Eis o paradoxo: como um país pode apoiar e falar em direitos humanos a partir da promulgação de uma lei contra a homossexualidade? 
O mundial de atletismo ocorrido no país, em meio à efervescência da decretação da lei, gerou manifestações de atletas que protestaram frente ao preceito. Os episódios com maior repercussão foram: o caso das suecas Moa Hjelmer e Emma Green-Tregaro, que pintaram suas unhas com as cores do arco-íris em apoio aos gays; e as atletas russas Kseniya Ryzhova e Tatyana Firova, que durante a cerimônia de entrega de medalhas do revezamento 4x400, beijaram-se nos lábios, quando se encontravam no pódio para o recebimento público das premiações. Diante do ocorrido, algumas manifestações de apoio à lei surgiram por parte de alguns atletas. Em meio à contestação, destacou-se a declaração da principal atleta russa, Yelena Isinbayeva, que manifestou-se a favor da lei.

A escolha de tal evento para mediar as interlocuções que faremos deve-se ao fato do mesmo polemizar questões intrínsecas aos estudos do corpo na modernidade, no que concerne às questões de gênero e preconceitos aos homossexuais, já que esses expressam comportamentos sexuais, sociais, culturais e políticos diferentes aos heterossexuais. Por ser um evento esportivo mundial, a questão do esporte e da homossexualidade também são centrais na pesquisa.

Assim o presente texto pretende investigar e analisar as demarcações e governo dos corpos no que tange as questões de gênero a partir de dados empíricos publicados na mídia aqui circunscrita à esfera digital - por meio do portal de internet "globo.com". A escolha do portal "globo.com" como fonte de dados empíricos se deve ao fato de que o Mundial de Atletismo 2013 teve a cobertura do canal por assinatura da "sportv", canal esse filiado a Rede Globo que tem como portal digital a "globo.com". Justificamos também a escolha do portal "gobo.com" pela sua representatividade hegemônica sustentada por uma grande empresa de comunicação.

No portal "globo.com" identificamos 12 reportagens que tratavam especificamente da polêmica da "lei anti-gay" e sua repercussão no Mundial de Atletismo. Tais dados foram coletados no período entre 31 de julho a 28 de Agosto de 2013, ou seja, 10 dias antes do evento (31 de julho a 9 de agosto), durante o evento (10 a 18 de Agosto de 2013) e 10 dias após o evento (19 a 29 de agosto), resultando em um total de 28 dias de coletas de material empírico.

Este estudo possui uma abordagem qualitativa, pois articula os "achados" da pesquisa com um determinado universo de sentidos e significações (MINAYO, 2010) próprios da vida cultural humana. É uma pesquisa descritivo-exploratória (TRIVIÑOS, 2010), pois traz fatos da realidade sem a preocupação de abordá-los no sentido de "busca ou fechamento de uma verdade", mas de descrever as características, destacando determinados pontos e refletindo sobre eles.

A análise das 12 reportagens referentes à polêmica a respeito da "lei anti-gay" e suas repercussões no Mundial de Atletismo de 2013, foi feita a partir de duas temáticas: "manifestações/protestos" e "polêmica Isinbayeva". Para a construção destes dois eixos temáticos foram lidas as 12 reportagens e por meio do recorte de episódios ocorridos no mundial foram perspectivadas associações/agregações de ocorrências que nos possibilitaram visualizar indicadores para uma análise e interpretação de dados. A análise ou tratamento dos dados foi feita de forma ensaística, onde os dados foram inferidos a fim de decodificarmos as temáticas abordadas nas reportagens.

Destarte, o texto foi organizado em dois momentos: a primeira parte foi reservada para uma discussão do corpo enquanto vetor de demarcação e governo; na segunda dissertamos e analisamos os dados a partir das temáticas aqui elencadas. 


\section{Corpo e gênero: demarcações e governo}

Somos e temos um corpo principalmente quando nos apropriamos de linguagens, pois este corresponde a vetores semânticos e sintáticos de diferentes construções e formas de existência: formas de ser corpo. Isso quer dizer que ele não é algo em si, mas sim uma construção, e cada nova maneira de construí-lo resulta numa nova maneira de se relacionar com ele individualmente e socialmente. Quando há uma alteração de concepção de corpo, há alteração também em tudo aquilo que é "corporado" enquanto comportamento social e todas as instâncias corporais existentes na sociedade (BÁRTOLO, 2007).

O corpo é um território de "demarcações", tanto no âmbito de identificação por meio de traços físicos ou características observáveis, bem como pelo fato do corpo ser um território demarcado pela linguagem que dá a ele uma capacidade de representação. O corpo é território de "demarcações" quando que ele ao mesmo tempo pode ser considerado sede de signos por ser atravessado por esses, assim como pode ser signo na medida em que pode representar algo e, assim, na expressão, atravessar outros corpos. É por essa dupla capacidade de "demarcar" e de ser "demarcado" que compreendemos o corpo como entidade passível de governar e de ser governado.

Historicamente, o corpo, sob o signo da genitália foi vetor de uma demarcação e governo. Sob o viés estruturalista, o fato de possuir tal ou qual genitália evidenciou o corpo enquanto um território de "demarcação" de gênero de duas formas: a descoberta da genitália e a inscrição de comportamentos. Entendemos isso na medida em que, para o estruturalismo, não basta só possuirmos uma genitália feminina ou masculina para nos tornarmos mulheres ou homens, também precisamos nos apropriar dos signos que indicam, subjetiva e objetivamente, comportamentos socialmente próprios para cada um dos sexos.

O pênis e a vagina seriam signos distintivos, de diferenças físicas, responsáveis por agrupar a pessoa no interior de um gênero biológico. A partir dessa classificação distintiva, a sociedade passa a se relacionar com um ou com outro de modos, também, diferentes. Dessa forma, o pênis e a vagina indicam, cada qual, como os outros na sociedade deverão se relacionar com aquele que é portador de um signo ou de outro. As categorias de gênero, dispositivo de demarcação e governo de corpos nada mais são do que uma gama de discursos e práticas, uma gama de técnicas e sistemas de julgamentos - de cunho moral e ético mediados por agenciamentos históricos de subjetivação na medida em que, além de ter um pênis ou uma vagina, o sujeito deverá internalizar os conteúdos e as formas de relacionamentos existentes na sociedade, entre os sujeitos, conforme suas diferenças e semelhanças.

Sob a ótica pós-estruturalista, não há divisão natural nem social de sexo e de gênero capaz de determinar e fixar o significado de um signo de diferença tal como o são o pênis e a vagina, ambos podem desencadear significações diversas. Podemos refletir que não há ligação entre o aparelho psíquico e as genitálias que determine que essas possuam relação com a cópula, com o homem, com a mulher. Lembrando que não estamos adentrando em problemáticas sociais e políticas que geram o hermafroditismo e a transexualidade. Para Butler (1998 p.25), "talvez o sexo sempre tenha sido gênero, de tal forma que a distinção entre sexo e gênero revela-se absolutamente nenhuma". Assim, pensar sexo como algo natural e gênero como algo cultural perde o sentido, pois:

Não há reflexividade ontologicamente inata para o sujeito que é então colocado dentro de um contexto cultural; é como se esse contexto já estivesse aí como o processo desarticulado da produção 
desse sujeito, escondido pelo enquadramento que situaria um sujeito ready-made numa teia externa de relações culturais (BUTLER, 2003 p.21).

Para Butler (1998), o gênero seria um fenômeno inconsciente e contextual, que não denotaria um ser substantivo, mas um conjunto de relações sociais e históricas convergentes. No entanto, pensar essa convergência inconsciente e histórica não seria negar dimensão biológica do corpo, pois, como já mencionava Canguilhem (2005), a sociedade regulariza o organismo, e a normatividade social se funde com a normatividade social. Essa é uma característica do ser enquanto vida.

O corpo enquanto vetor de gênero é um agenciamento em constante construção e o sujeito se constrói enquanto gênero através de fluxos assimétricos. O sujeito é o contexto em que ele é produzido. Esse sujeito e esse contexto, na menção de Deleuze e Guattari (1996), são máquinas que se retroalimentam: "O que há por toda a parte são máquinas e sem qualquer metáfora: máquinas de máquinas, com suas ligações e conexões. Uma máquina-órgão está ligada a uma máquina-origem: uma emite o fluxo que a outra corta" (DELEUZE \& GUATTARI, 1966, p.7). Neste sentido, "nenhum sujeito é seu próprio ponto de partida; e a fantasia de que o seja só pode desconhecer suas relações constitutivas refundindo-se com o domínio de uma externalidade contrabalançadora" (BUTLER, 2003 p.18).

No entanto, não podemos esquecer que abordar o corpo sob o viés do discurso e da linguagem não significa negar sua materialidade. Neste sentido, Butler (1998, p. 26) menciona que:

O corpo postulado como prévio ao signo é sempre postulado ou significado como prévio. Essa significação funciona mediante a produção de um efeito de seu próprio procedimento, o corpo que ela todavia e simultaneamente afirma descobrir como aquilo que precede a significação. Se o corpo significado como prévio a significação é um efeito de significação, então o estatuto mimético ou representativo da linguagem, que afirma que o signo segue os corpos como seus espelhos necessários, não é de forma alguma mimético; ao contrário, é produtivo, constitutivo, pode-se até dizer performativo, visto que esse ato de significação produz o corpo que então afirma encontrar antes de qualquer significação.

Louro (2010) destaca que as identidades de gênero articulam-se em variadas combinações e são construídas por redes de poder, bem como são constituídas delas, o que evidencia as relações políticas que formam estas identidades. O que é necessário é compreender que instituições sociais, doutrinas, normas, leis, política, são instâncias constituídas por representações de feminino e masculino, e desempenham um papel importante para a produção, manutenção e ressignificação das representações de gênero que podemos ver "demarcadas" nos corpos "femininos" e "masculinos".

\section{Dialogando com os dados}

A primeira temática trata das questões das manifestações/protestos ocorridas no Mundial fica manifesta em 5 títulos das 12 reportagens. Porém, a temática aparece em 8 das 12 reportagens.

No dia 03/08/2013, o "globo.com" publicou a matéria na qual informa que: 
a confirmação de que as leis anti-gays da Rússia vão vigorar durante os Jogos de Inverno, que serão realizados em Sochi em fevereiro de 2014, causou o descontentamento de alguns atletas olímpicos que, em protesto, vão participar neste fim de semana de uma parada contra a legislação que decreta prisão para quem fizer propaganda homossexual durante as Olimpíadas. (GLOBO ESPORTE 1, 20013)

Neste sentido, Butler (2003) menciona que a política exige um sujeito especificamente demarcado em sua identidade na medida em que pressupõe um sujeito estável, com identidade fixa. O que demonstram a reportagem é a imposição de uma norma que tenta regular as identidades de gênero por meio de uma lei que busca a classificação e demarcação dos corpos sexuados para, então, pensar e efetivar políticas específicas para eles. Isso implica uma estratégia para simplificar a sociedade no sentido de simplificar os princípios teóricos e as ações metodológicas do governante diante da incontrolável multiplicidade de situaçõesproblema que se impõem ao seu controle.

As categorias de identidades nunca se dão por elas mesmas, mas sim por um sistema de normas que as regulam (BUTTLER, 1998) e que pretendem governar e demarcar esses corpos. As identidades feminina e masculina são efeitos das normas de gênero, o que podemos visualizar no caso da lei anti-gay - a regulação de identidades de homem e mulher e o governo dos corpos destes mediante um sistema de normatização que necessita simplificar o complexo com o objetivo de poder exercer um governo supostamente universalista que se perturba diante da multiplicidade imprevisível da vida.

A partir das formulações de Michel Foucault, os postulados da heterossexualidade como uma condição uniforme e um significado essencial deram lugar à noção de que a sexualidade varia consideravelmente tanto no interior das sociedades como entre elas. (SOARES, 2010). Segundo Weeks (1999), o termo sexualidade é empregado como "uma descrição geral para a série de crenças, comportamentos, relações e identidades sociais e históricos". Afirma ainda que "a sexualidade, embora tendo como suporte um corpo biológico, deve ser vista como uma construção social, uma invenção histórica, pois o sentido e o peso que lhe é atribuído são modelados em situações sociais e concretas".

Para a superação da demarcação e governo de gênero, Butler (2003) sugere que a política se desloque no sentido não mais de estabelecer um sujeito de identidade fixa, mas que deixe em aberto a questão da identidade, que ela seja algo que não organize a pluralidade, mas que a mantenha aberta sob permanente vigilância. Se as identidades deixassem de ser fixas como premissas de um silogismo político, e se a política não fosse mais compreendida como um conjunto de práticas derivadas dos supostos interesses de sujeitos prontos, uma nova configuração política surgiria (BUTLER, 2003). Uma política menos programática e, portanto, mais atenta às dinâmicas das realidades sociais, culturais, política e econômicas que surgem enquanto problemas no campo das relações humanas.

Neste sentido, alguns atletas se manifestaram contra essa política de apagamento das sexualidades. Numa reportagem de 3 de Agosto de 2013, o portal noticia que dois atletas olímpicos canadenses de esportes de inverno, Mike Janyk e Mercedes Nicoll, iriam participar de uma parada gay na cidade de Vancouver contra as leis da Rússia. O Comitê Olímpico Canadense já tinha se posicionado contra a lei adotada pela Rússia e o porta-voz do comitê declarou: "Praticar esportes é um direito humano e deve estar disponível para todos, independentemente de raça, gênero ou orientação sexual" (GLOBO ESPORTE 1, 2013).

No dia 17 de agosto de 2013 foi publicada a notícia de que no cerimonial de premiação da prova do revezamento $4 \times 400$ feminino, duas das quatro atletas medalhistas de 
ouro deram um beijo "selinho" para comemorar o ouro no pódio. As corredoras Kseniya Ryzhova e Yulia Gushchina foram fotografadas durante a comemoração, logo após receberem a medalha.

$\mathrm{Na}$ Rússia, é considerado comum que tanto homens quanto mulheres troquem beijos quando estão entre amigos ou em família. Porém, a cena chama atenção na semana em que a polêmica lei do país ganhou mais repercussões. No dia seguinte à publicação da imagem, no mundo corria a polêmica: seria ou não o beijo um protesto à lei anti-gay? O "globo.com" publica que, em entrevista ao jornal britânico "The Guardian", Ryzhova esclareceu que o ato não teve nada a ver com a sexualidade das atletas:

- Foi somente (uma demonstração) de felicidade da nossa equipe. Se as pessoas querem escrever sobre qualquer tipo de besteira sobre a gente, deveriam pelo menos saber que nós somos ambas casadas - disse a atleta, lembrando que as quatro corredoras se beijaram na boca após receberem a medalha de ouro. (GLOBO ESPORTE 2, 2013).

Outro episódio foi o caso das atletas suecas Moa Hjelmer e Emma Green-Tregaro, que pintaram as unhas com as cores do arco-íris para fazer um protesto contra a lei. A atleta Emma (uma atleta homossexual assumida), da prova do salto em altura, competiu as eliminatórias com as unhas pintadas com as cores do arco-íris. No dia seguinte ao protesto, a atleta disputou a final da prova do salto em altura com as unhas pintadas de vermelho.

Os atletas que protestam não conseguem visualizar um lugar onde seu "eu" seja contemplado. O eu é constituído por posições e essas posições não são meros produtos teóricos, mas princípios organizadores totalmente imbuídos de práticas materiais que produzem um "sujeito" viável (BUTLER, 1998). Frente à política que exige um sujeito "universal", os atletas clamam contra seu apagamento singular. Nesse sentido, protestar contra a lei é ir contra as formas de regulação de comportamento que a mesma dita; é denunciar algo que não os representa. O que está evidente é que os protestos dos atletas reivindicam pensar os corpos pela questão da diferença, que existem outros modos para se pensar as relações entre gêneros: pensando a diferença na diferença.

O protesto aqui fica em nível de interrogação e repúdio contra uma premissa fundamentalista que constrói um sujeito que serve e é eficaz para uma política rigidamente programática. Assim, percebemos que esses sujeitos tentam se deslocar de forma intencional em meio às relações de poder, fazendo com que os efeitos instituídos pela lei anti-gay não seja unilinear quanto à sua direção, e desta forma escapem desse teatro de operações materiais e simbólicas. Na menção de Butler (1998, p. 17):

Dentro do contexto político do pós-colonialismo contemporâneo, talvez seja especialmente urgente sublinhar a própria categoria do "universal" como lugar de insistente disputa e ressignificação. Tendo em vista o caráter contestado do termo, supor desde o início uma noção instrumental ou substantiva do universal é impor uma noção culturalmente hegemônica sobre o campo social.

Lutar e evadir-se dessas representações caracteriza aquilo que escapa às normas, evidenciando fissuras, fossos e mostrando as instabilidades dessa construção (BUTLER, 2010). Fugir dessa formação identitária de gênero, como nos mostra Butler (2010), é como se os corpos, que fogem da norma não fossem legitimados fora delas; é como se estes corpos formassem um 
campo de deformação, pois vão contra a norma ou forma regulatória de ser e de se expressar. São corpos que não se enquadram na inteligibilidade da cultura, já que toda inteligibilidade implica sistemas categoriais ou taxionômicos metafísicos responsáveis por organizar a realidade material. Quando algo não compõe o campo simbólico da cultura, será considerado um risco, um desvio, algo excluído das categorias e, portanto, da metafísica social dos sujeitos.

As unhas pintadas da atleta Emma foram o estopim para estourar a polêmica que envolveu a atleta russa Yelena Isinbayeva que, após receber o ouro na prova do salto com vara, condenou a atitude. A temática que ora apresentamos trata das questões que envolvem as polêmicas de Isinbayeva. Esse tema apareceu em 3 títulos e no corpo de 9 das 12 reportagens.

Isinbayeva soltou o verbo contra os atletas que protestavam contra a lei anti-gay russa:

- Se nos permitirmos promover e fazer esse tipo de coisas, tememos muito por nossa nação porque nos consideramos normais, com um padrão. Nós apenas vivemos com homens ao lado de mulheres, e mulheres ao lado de homens. Tudo deve estar bem. Isso vem da história. Nós nunca tivemos problemas assim na Rússia. E não queremos ter problemas assim no futuro - afirmou. (GLOBO ESPORTE 3, 2013).

Para a russa, os competidores estrangeiros precisavam respeitar os costumes de seu país:

- É desrespeitoso com o nosso país. É desrespeitoso com nossos cidadãos porque somos russos. Talvez sejamos diferentes de outros europeus e de pessoas de diferentes países. Nós temos nossa casa e todos devem respeitar. Quando chegamos a outros países, tentamos seguir as regras deles. (GLOBO ESPORTE 3, 2013).

Após essas declarações, Isinbayeva foi acusada de homofobia e veio a público se retratar:

- Quero deixar claro que respeito os pontos de vista de meus companheiros atletas e quero expressar de maneira firme que me oponho a qualquer discriminação contra a comunidade gay a respeito de sua sexualidade (o que iria contra a Carta Olímpica). O inglês não é minha língua materna e acredito que aconteceu um mal-entendido quando falei ontem. O que queria dizer é que as pessoas devem respeitar as leis de outros países, particularmente quando são convidados. (GLOBO ESPORTE 3, 2013)

A primeira fala de Isinbayeva, quando a mesma menciona que não se pode "promover esse tipo de coisa", pois possuem uma nação normal, com um padrão e que convivem apenas com homens ao lado de mulheres e vice-versa, representa bem a noção de gênero construída pela matriz heterossexual. Após isso, ela usa um argumento que quebra com o primeiro, quando, ainda nessa mesma fala, a atleta enfatiza que isso já vem da história. De fato, quanto a isso, a russa está certa, pois, como nos menciona Alós (2012), é apenas dentro da cultura e da história que o corpo e o sexo expressam sentido e significado, ou seja, tornam-se compreensíveis, aceitos, inteligíveis. Ainda segundo o autor, a partir dessa noção, a categoria de gênero, assim como algumas noções de "normal" e "anormal" a respeito de algumas sexualidades, deixam de serem "verdades", ou possuírem uma essência transcendental e inquestionável, e podem passar a serem questionadas, repensadas como construto histórico-cultural. 
A partir do momento em que corpos e gêneros fogem dos limites simbólicos demarcados, são considerados não legítimos, ou seja, anormais. Porém, como destaca Alós (2012), os corpos que ultrapassam esses limites dão margem e brechas para questionar a própria noção do que é acatado como culturalmente legítimo.

Neste sentido, também questionamos: a noção da legitimidade do gênero a partir do normal ou do anormal é vista nos corpos que não se encaixam nos limites da lei ou na própria lei que é pautada numa matriz heterossexual? A noção de gênero "normal" ou "anormal" existe nos próprios corpos ou no discurso da lei e dos que a defendem? Quem estabelece as normas e que contestações elas produzem? Quais as origens das operações dessa construção? Quais as origens desse apagamento para além do binário homem x mulher?

A partir de formas de gênero que transcendem o binarismo prescrito pela matriz heterossexual, essas identidades de gêneros subversivas, que abrem fissuras para desestabilizar as amarras que prendem os corpos na inteligibilidade estrutural dessa matriz ou modelo racional, ocasionando uma ressignificação subversiva de corpo, sexo e gênero (ALÓS, 2012), abrindo as portas da própria estrutura/matriz. Desta forma, segundo Butler (1998, p.22):

Para que o sujeito seja um ponto de partida prévio da política é necessário adiar a questão da construção e regulação política do próprio sujeito, pois é importante lembrar que os sujeitos se constituem mediante a exclusão, isto é, mediante a criação de um domínio de sujeitos desautorizados, présujeitos, representações de degradação, populações apagadas da vista.

Sabedores de que a Rússia sediaria dois grandes eventos de visibilidade internacional: as Olímpiadas de Inverno de2014, e a Copa do Mundo de Futebol de 2018, algumas polêmicas e manifestações frente à lei anti-gay acabaram respingando no agendamento desses eventos. Com isso, podemos notar que a polêmica da lei "anti-gay" promulgada pelo governo russo pode ser encontrada além da relação entre Estado e indivíduos, pois seus efeitos ganharam contornos interinstitucionais e internacionais. A noção de subversão à lei não pode ser definida em termos factuais. Isto é, uma ação pode ser criminosa ou não a depender da lei que a interpreta. Para o Estado russo, realizar qualquer apologia à homossexualidade é crime. Já na sociedade norteamericana, crime significa justamente o contrário: proibir que alguém divulgue a homossexualidade (liberdade de expressão).

A lei russa e seus defensores não titubeiam ao alertarem que não se trata de uma criminalização da orientação sexual de alguém, mas sim da expressão propagandista envolvendo comportamentos homossexuais. A legislação russa, portanto, irá proteger o direito da pessoa ser homossexual, desde que ela não se expresse. Em outras palavras, desde que isso não seja público e não caracterize propaganda, isto é, a tentativa de convencer os demais a optar por uma dada orientação sexual ou de influenciá-los de algum modo, em especial os jovens. Em meio a esse impasse, os russos que se declararam solicitam que os estrangeiros respeitem as normas do país. Ao mesmo tempo e em igual medida, os atletas estrangeiros, homossexuais ou não, parecem reivindicar que a nação russa respeite seus costumes e valores.

Entretanto, o problema se agrava quando, além das instituições esportivas e do Estado russo, outra instituição, o Movimento Gay da Rússia, representada por seu líder, entra em cena ao criticar a defesa da atleta Isinbayeva dirigida à lei "anti-gay"; principalmente porque, a nosso ver, essa última se pronuncia argumentando que a referida lei representa a nação russa e, portanto, todos os russos, ao exigir que os estrangeiros respeitem suas normas. Nikolai Alexeyev, conforme nosso referencial teórico pós-estrutural, aparece como uma fissura nos limites do discurso de unidade cultural promulgado por Isinbayeva, apontando que a homossexualidade consiste em ser 
uma existência ou modo de ser para além das culturas locais e seus conflitos internacionais. A sexualidade, mais uma vez, se apresenta como um rasgo nas estruturas culturais, de modo a fazer com que essas se reestruturem, considerando esse dado como parte da vida pensada e não como anomalia categorial. Por isso, a lei russa em pauta não representa todos russos e seus sentimentos.

Elementos de uma outra estrutura considerada estrangeira atravessam o núcleo e as periferias de estruturas que tentam organizar comportamentos díspares. Na prática, a sexualidade atravessa de surpresa a estrutura institucional do esporte, para a qual a categorização ou divisão entre masculino e feminino estava segura na distinção entre genitálias: pênis ou vagina. No interior da classe genitália atravessam diferenças de sentido. Mas o curioso de tudo isso é que a homossexualidade no esporte não abala a estrutura do esporte em si, mas, por meio dele, perturba uma outra estrutura externa em termos de semelhança diagramática: os Estados e suas ilusões de sociedade homogênea e hegemônica.

\title{
Considerações finais
}

Retomando o objetivo de nosso artigo que foi investigar e analisar as demarcações e governo dos corpos no que tange as questões de gênero a partir de dados empíricos veiculados no portal "globo.com" entendemos que corpo do outro e o meu próprio são enigmas que nos oferecem pistas, indícios, signos, sintomas que desconstroem todo tipo de taxonomia e, portanto, o contexto cultural que a sustenta. Nessa desconstrução taxionômica, o exercício de desconstruir não deve ser visto como sinônimo de censura ou aniquilamento, pelo contrário, trata-se de se libertar de amarras epistêmicas e metafísicas para que os sentidos de gênero não fiquem presos a uma matriz antecipatória que não deixe emergir outros significados. É um desafio no sentido de emancipar o gênero de ontologias que os condenam a matrizes de demarcação e governo.

Desta forma, a homossexualidade será vista sob o viés epistemológico de outras estruturas relacionais para além daquelas que até agora a enxergaram. É nesse ponto que o pós-estruturalismo oferece uma nova saída. A saída da proliferação das diferenças, a proliferação de versões sobre a estrutura. Para começar a mudar é necessário experimentar o olhar do outro em mim enquanto o olhar da diferença.

As políticas de Estado pautadas teórica e metodologicamente no estruturalismo buscaram organizar a realidade formada pelas relações entre os viventes segundo seus respectivos sistemas categoriais cujas bases estão fixadas na epistemologia e na metafísica ocidentais. Já o pós-estruturalismo, enquanto corrente teórico-metodológica, defende que os modelos mentais devem se transformar em função dos devires apresentados pelos viventes. Nesses termos, pensar os desafios governamentais em uma era democrática significa que as leis devem garantir o bem-estar e o convívio humano de todos. Portanto, toda lei que exclui ou criminaliza um sujeito ou um grupo deverá ser revista para se adequar à necessidade das pessoas, já que as leis e as normas só têm sentido para preservar a humanidade.

\section{THE ANTI-GAY LAW IN RUSSIA: DEMARCATIONS AND GOVERNMENT OF THE BODIES AT 2013 WORLD CHAMPIONSHIPS IN ATHLETICS}

\begin{abstract}
The article aims to investigate the demarcations and the bodies' governments into the gender questions occurred at the 2013 Moscow World Championships in Athletics, discussing the polemic caused by the Russian anti-gay law. The study has a qualitative approach made
\end{abstract}


through a descriptive-exploratory research. The empirical data was taken of publications of the site "globo.com". We analyzed 12 news on two themes: "manifestations/protests" and "the Isinbayeva controversy". We observed, as results, that the athletes' manifestations were in a way to claim against their singular erasure of a politic that demands a "universal" subject.

Keywords: 2013 World Championships in Athletics in Russia; Anty-gay law; Sport; Homosexuality.

\title{
LA LEY ANTI-GAY RUSA: DEMARCACIONES Y GOBIERNO DE LOS CUERPOS EN EL MUNDIAL DE ATLETISMO 2013
}

\begin{abstract}
Resumen
Artículo cuyo objetivo es investigar las demarcaciones e el gobierno de los cuerpos en lo que atañe a los temas de género ocurridos en el Mundial de Atletismo de Moscú en el año 2013 frente a las polémicas causadas por la ley anti-gay rusa. Fue un estudio de abordaje cualitativo hecho a partir de una investigación descriptiva y exploratoria. Los datos empíricos utilizados para conjeturar los objetivos del texto se tomaron de las publicaciones hechas en el portal de internet "globo.com". Nuestro análisis se limitó a 12 reportajes y se ha realizado mediante dos temas: "manifestaciones/protestas" y "controversia Isinbayeva". Hemos observado que las manifestaciones de atletas fueron hechas en el sentido de clamar en contra su borrado singular ante una política que requiere un sujeto "universal".
\end{abstract}

Palabras clave: Mundial atletismo Rusia 2014; Ley anti-gay; deporte; homosexualidad.

\section{Referências}

ALÓS, A. P. A letra, o corpo e o desejo: masculinidades subversivas no romance latinoamericano. Florianópolis: Mulheres, 2012.

ANDRADE, S. S. Mídia Impressa e Educação dos Corpos Femininos. In: Corpo, Gênero e Sexualidade: um debate contemporâneo na educação. Petropólis. Rio de Janeiro, 2003. p.108 $-121$.

BÁRTOLO, J. Corpo e Sentido: estudos intersemióticos. Civilhã: Portugal. Livros LabCom, 2007.

BUTLER, J. Corpos que pesam: sobre os limites discursivos do "sexo". In: LOURO, G. L. O corpo educado: pedagogias da sexualidade. Belo Horizonte: Autêntica, 2010 p. 151-172.

Problemas de gênero: feminismo e subversão da identidade. Tradução de Renato Aguiar. Rio de Janeiro: Civilização Brasileira, 2003.

Fundamentos contingentes: o feminismo e a questão do "pós-moderno". Cadernos Pagu trajetórias do gênero, masculinidades, Campinas, v. 11, p. 11-43, 1998.

CANGUILHEM, G. O problema das regulações no organismo e na sociedade. In: CANGUILHEM, G. O. Escritos sobre a medicina. Tradução de Vera Avellar Ribeiro. Rio de Janeiro: Forence Universitária, 2005. (Fundamentos do saber) p. 71-88 
DELEUZE, G.; GUATTARI, F. O anti-Édipo. Capitalismo e esquizofrenia. Lisboa: Assírio \& Alvim, 1996.

GLOBO ESPORTE 1. Atletas olímpicos vão participar da parada gay contra leis da Rússia. Rio de Janeiro, 2013. Disponível em: http://globoesporte.globo.com/olimpiadas-deinverno/noticia/2013/08/atletas-olimpicos-vao-participar-de-parada-gay-contra-leis-da-russia.html. Acesso: 28/08/2013.

GLOBO ESPORTE 2. Russa explica que beijo no pódio no mundial não foi protesto a lei antigay russa. Rio de Janeiro, 2013. Disponível em: http://globoesporte.globo.com/atletismo/noticia/2013/08/russa-explica-que-beijo-no-podio-nomundial-nao-foi-protesto-lei-anti-gay.html. Acesso: 28/08/2013.

GLOBO ESPORTE 3. Isinbayeva se retrata e diz ser contra discriminação: "foi um malentendido". Rio de Janeiro, 2013. Disponível em: http://globoesporte.globo.com/atletismo/noticia/2013/08/isinbayeva-se-retrata-e-diz-ser-contradiscriminacao-foi-um-mal-entendido.html . Acesso: 28/08/2013.

LOURO, G, L. Currículo, gênero e sexualidade: o "normal", o "diferente" e o "exêntrico". In: LOURO, G. L.; FELIPE, J.; GOELLNER, S. V. Corpo, gênero e sexualidade: um debate contemporâneo na educação. 6. ed. - Petrópolis, RJ: Vozes, p. 41-52, 2010.

MINAYO, M.C. de S. Pesquisa social: teoria, método e criatividade. 29a ed. Petrópolis: Vozes, 2010.

SOARES, R.; Fica comigo gay: O que um programa de TV ensina sobre uma sexualidade juvenil? In: LOURO, G. L.; FELIPE, J.; GOELLNER, S. V. Corpo, gênero e sexualidade: um debate contemporâneo na educação. 6. ed.- Petrópolis, RJ: Vozes, p. 136- 148, 2010.

TRIVIÑOS, A.N.S. Introdução à pesquisa em ciências sociais. São Paulo: Atlas, 2010.

WEEKS, J. O corpo e a sexualidade. In: LOURO, G. (org.) In: O corpo educado: Pedagogias da sexualidade. Belo Horizonte: Autêntica, p. 35-82. 1999.

Recebido em: 18/02/2015

Revisado em: 28/05/2015

Aprovado em: 15/07/2015

Endereço para correspondência:

Fabio Zoboli

zobolito@gmail.com

Universidade Federal de Sergipe,

Avenida Marechal Rondon, S/n

Jardim Rosa Elze, São Cristóvão - SE, 49100-000 